\title{
A estética da personagem de horror no Brasil: reflexões sobre Zé do Caixão e 0 Morto do Pântano
}

\author{
Marcelo Briseno Marques de Melo' \\ Giovani Pagliusi Lobato e Moura² \\ Universidade Metodista de São Paulo
}

\begin{abstract}
Resumo
Esse artigo busca entender as personagens ficcionais Zé do Caixão e O Morto do Pântano como referências de estrutura e de estilo do gênero horror nas histórias em quadrinhos brasileiras. Por um escopo metodológico baseado em leitura observativa, serão tratados aspectos dessas personagens cujas referências se encontram na literatura clássica ocidental. Para chegarmos a essas referências, pretende-se traçar um breve panorama histórico do horror e de suas personagens em três correntes históricas correlacionadas da literatura: 1. No séc. XIII, enquanto roupagem de controle religioso-social, que causava sentimentos de medo e respeito pelo sobrenatural; 2 . No começo do séc. XIX, enquanto gênero literário consolidado, que oferecia originalidade e autonomia para as narrativas; 3 . Do séc. XIX em diante, com a proliferação do horror enquanto referência artística e de consumo massificado.
\end{abstract}

\section{Palavra-chave}

Horror; Terror; Histórias em Quadrinhos; Zé do Caixão; O Morto do Pântano.

\section{Introdução}

O domínio de narrar acontecimentos de ficção que causam horror em forma de textos e imagens sempre foi uma tarefa técnica desafiadora e de alto nível em termos de representação. O tempo da realidade mundana e o tempo desse tipo de narrativa ficcional costumam ser desalinhados em sua natureza. A tentativa de compreender ou de encontrar respostas pelo escopo um do outro costuma gerar

\footnotetext{
1 Marcelo Briseno Marques de Mello é Doutor em Comunicação Social pela Universidade Metodista de São Paulo (UMESP). Coordenador do curso de Rádio TV e Internet da mesma Instituição. Diretor Financeiro da Sociedade Brasileira de Estudos Interdisciplinares na Área de Comunicação - INTERCOM. marcelo.melo@ metodista.br
}

2 Giovani Pagliusi Lobato e Moura. Mestre pelo Programa de Pós-Graduação em Comunicação e Semiótica (PUCSP). Leciona na Graduação do curso de Rádio e Televisão da UMESP. giovasstrasser@yahoo.com.br

Revista Ícone (ISSN 2175-215X) • DOI: 10.34176/icone.v17i3.242278

Recife, Vol. 17, N. 3, 380-395, ○ 2019 PPGCOM/UFPE.

Artigo recebido em 15 dez. 2018 e aprovado em 12 ago. 2019.

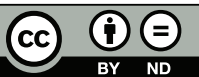


um caminho ainda mais obscuro, mas talvez a procura por interfaces possa ser considerada a fórmula de sucesso das personagens ficcionais horríficas que de fato assumem características nefastas e duvidosas ao olho mundano.

O entendimento do horror como instrumento de sucesso na captação de audiências nas histórias em quadrinhos, no cinema e na televisão implica em saber, primeiramente, seus princípios estruturais em suas origens enquanto gênero literário. Não caberá neste texto tratar o horror em uma ampla linha cronológica como gênero literário e seus desdobramentos midiáticos. Nesse sentido, cabe dizer que este gênero narrativo na literatura se fez presente em toda a história da civilização a partir do momento em que o homem começou a partilhar experiências, como já notado por H.P. Lovecraft em O horror sobrenatural na literatura (1987), escrito originalmente em 1927.

Antes de mais nada, porém, e para não entrarmos em um possível embaralhamento de significados, devemos deixar claro que existe uma distinção entre os termos horror e terror, ao mesmo tempo em que tais termos se valem, em geral, como elementos estruturais de uma mesma continuidade narrativa. É prudente, então, levar em consideração a reflexão da autora de ficção gótica Ann Radcliffe (1826) sobre a distinção desses termos.

Em linhas gerais, o terror é descrito por ela como apreensão ou sentimento que precede uma possível experiência horrível. A literatura fantástica, gênero literário ou variedade da literatura de ficção que tem como característica a narração de fatos inexplicáveis como se fossem reais ${ }^{3}$, é o formato de maior sucesso ao envolver personagens e os ambientes em atmosferas que combinam o padrão literário psicológico que geralmente produz no leitor o sentimento de medo intenso (ou terror). Em contrapartida, o horror é, pra Radcliffe, a sensação de repúdio que geralmente ocorre depois de o acontecimento se desdobrar de maneira visual e sonora, enquanto experiência concreta, e não antecipatória. Ou seja, o horror é a sensação que sucede um sentimento de antecipação terrível ou extremamente desagradável. Podemos dizer, então, que o terror está relacionado à expectativa, à ansiedade diante do estranho ou do incerto, causando o sentimento de medo, enquanto o horror é a experiência que se adquire durante e depois do acontecimento em si.

Mesmo antes do surgimento do horror/terror como gênero, a literatura já se valia com frequência desses sentimentos. A maioria das vezes em que a literatura entra em conflito com o realismo é quando monstros ou criaturas inimagináveis

3 A Literatura Fantástica tem sua essência na narração de acontecimentos que não são racionalmente explicáveis, ou seja, o fantástico é composto de elementos que, dentro do que conhecemos como as leis da realidade, não são reconhecidos como possíveis: monstros, criaturas sobrenaturais, inferno, purgatório, punição após a morte etc. É no momento de dúvida das personagens (e leitores) diante do sobrenatural, do estranho e do insólito, que esse gênero se instaura e toma forma. O fantástico se dá quando o leitor decide aceitar a possibilidade da existência de novas leis da natureza ou de ações inimagináveis na realidade do cotidiano, fazendo com que esses acontecimentos se tornem possíveis de serem apresentados como uma face da realidade ou como um paradoxo da mesma. Autores como H.P. Lovecraft, Franz Kafka, Maurice Blanchot e estudiosos como Noel Carroll e Tzevtan Todorov ajudam, com suas obras, a difundir e compreender literatura fantástica. 
começam a habitar as narrativas mitológicas, religiosas, históricas ou lendárias, formando uma espécie de simbolismo fantástico, impressionando leitores e espectadores - sejam eles egípcios, gregos, indianos, persas, romanos, etc. A história da literatura, portanto, contribui para a caracterização de criaturas de vários significados, divinas ou subterrâneas, bíblicas ou bélicas, cultuadas ou famigeradas, cujo propósito comum ao serem criadas - podemos dizer sem rodeios - é o de produzir medo, respeito e controle, sejam elas criaturas religiosas, míticas, lendárias.

Na obra fundamental da cultura cristã ocidental A Divina Comédia, de Dante Alighieri, o poema épico e teológico escrito no século XIV, é possível perceber que a peregrinação de Dante (como personagem) chancelada pelo poeta romano Virgílio pelo Inferno, apresentando a maioria das correntes teológicas de época, é configurada pela reação mundana de "ficar-se horrorizado" com aquilo que está acontecendo diante de seus olhos (dos olhos de Dante e, por conseguinte, do leitor), e que por ele é compreendido como algo excepcional e insólito.

No Canto I do Inferno, Dante se encontra em uma floresta selvagem (mas ainda na realidade mundana) e é impedido por três feras de seguir seu caminho. Podemos perceber, em sua narração, o sentimento antecipatório do terror e também o horror diante da aparição das estranhas feras que interrompem seu caminho:

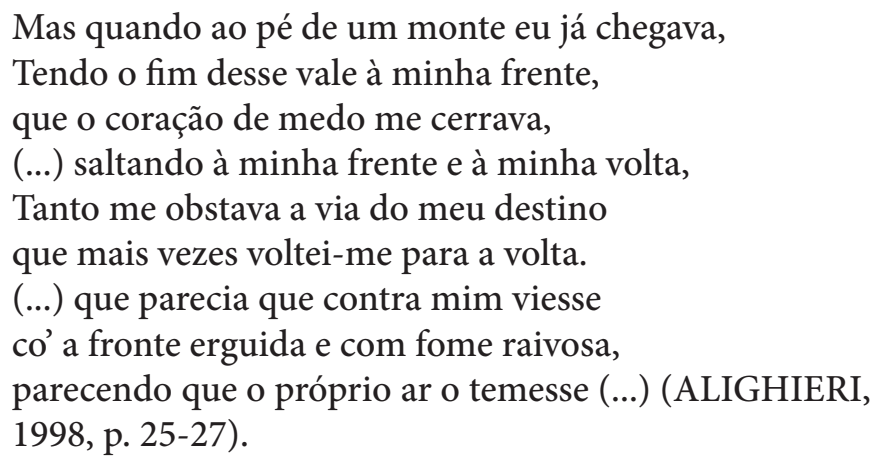

Considerando A Divina Comédia como obra de referência da cultura literária ocidental, ao trabalhar o horror como desdobramento de um relato de terror, ela pode ter contribuído para chancelar a experiência do horror (na formalização literária) como função artística consolidada. Sua presença influenciou a caracterização de personagens e a relação delas com ambientes que os cercam, fomentando certa organização do horror como gênero e também como consequência natural perante o testemunho do estranho e do indescritível.

Uma das funções essenciais da obra de Dante foi a de demonstrar as horríveis consequências de uma vida desviada da fé ocidental traduzida no cristianismo. Para tal, a elaboração de uma peregrinação passando por ambientes de punição habitados por criaturas das mais terríveis naturezas sugere uma função social da história de horror como possível mecanismo de controle da ação humana 
enquanto convívio com o outro e com o mundo.

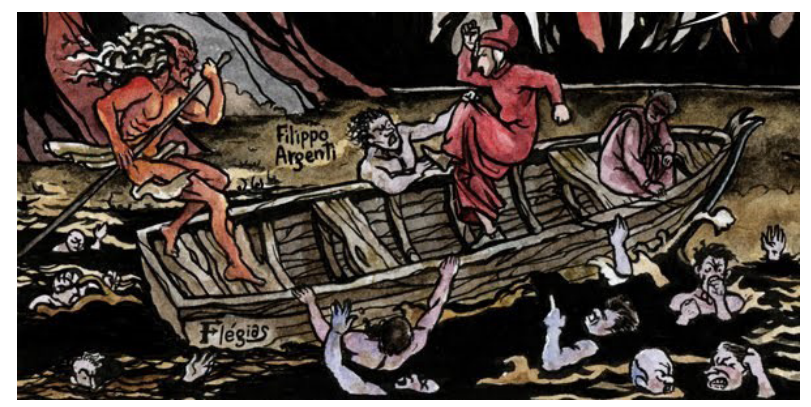

Figura 01: Flégias e o Estige - Virgílio e Dante na borda do pântano Est

Fonte: Piero Bagnariol / Editora Peirópolis

Em outras palavras, todo o primórdio histórico de uma entidade, um lugar, uma organização ou uma instituição está intimamente ligado à criação de uma ou mais criaturas que destilam o medo para fins de controle social. Porém, a utilização desse controle, geralmente feita por organizações seculares, pode ser bem variada de acordo com a evolução da história humana. Temos, por exemplo, na história do Cristianismo sintetizada na Bíblia, a criatura de maior referência: Lúcifer.

O propósito do mais famoso deles Lúcifer ou Satanás, pelo menos, é assustar aqueles que creem nas escrituras como obras escritas ou ditadas por Deus. Ao se observar o livro sagrado, por esse aspecto pode-se entender melhor como o sobrenatural e o terror se consolidam nas mais diversas formas de representação do medo no Ocidente, ao longo de séculos, em narrativas de mitos e lendas até chegar à Idade Moderna (JUNIOR, 2008, p. 40).

Seria imprudente não referenciar o Anjo Caído (Lúcifer) e suas várias faces como uma recorrente personificação do insólito em personagens de ficção - inclusive nas histórias em quadrinhos, que são nosso objeto neste artigo. No Brasil e no mundo, Lúcifer é lugar-comum de tramas que envolvem desgraça, sensação 
sufocante, medo, senso do morbidez e de presença maléfica do sobrenatural.

Porém, não se deve confundir a presença de criaturas e monstros mitológicos na literatura em geral com o estabelecimento do horror como gênero literário. O florescimento do horror como gênero aconteceu na segunda metade do segundo milênio da era Cristã, alavancado pelo surgimento dos contos de fadas, cuja origem "está relacionada à literatura cortesã da Idade Média por volta do século VII, e nas novelas de espada" (JUNIOR, 2008, p. 59).

Os contos de fadas popularizados na Europa a partir dos séculos XVII e XVIII traziam seres de aparência duvidosa que representavam o Mal, a sensação de medo, e eram confrontados pelos heróis e heroínas das tramas. Tais tramas envolviam elementos sobrenaturais como magia, metamorfoses, encantamentos e animais falantes. Como descreve Gonçalo Junior, "os primeiros textos [dos contos de fadas] eram marcados por situações que iam do adultério e do incesto ao canibalismo e às mortes hediondas" (2008, p. 59).

$\mathrm{Na}$ evolução do horror como gênero literário no começo do século XIX, surgiram autores que começam a combinar a personificação insólita das criaturas assustadoras com o elemento espacial, ou seja, o plano emocional também evoluía de acordo com o seu entorno. Segundo Melo, que adota a concepção de Lovecraft, "o verdadeiro conto de horror exige uma atmosfera e um ambiente de terror, nos quais agem forças externas, não naturais, para gerar uma sensação sufocante e inexplicável de horror" (MELO, 2011, p. 23).

Citado por Melo, Howard Phillips Lovecraft (EUA, 1890-1937), considerado uma das referências do gênero horror na literatura do século XX, deixa claro que o critério de autenticidade desse gênero está menos no recorte das tramas do que em suas possíveis sensações como efeitos sociais. Para ele, ao causar pavor ou certo dano na crença social, o horror se torna uma categoria autêntica de literatura. Para Lovecraft:
O único teste para o verdadeiro horror é simplesmente este, se suscita ou não no leitor um sentimento de pro- funda apreensão, e de contato com esferas diferentes e forças desconhecidas: uma atitude sutil de escuta ofe- gante, como à espera do rufar de asas negras ou do roçar de entidades e formas nebulosas nos confins extremos do universo conhecido (LOVECRAFT, 1987, p. 6).

Ao combinar o ambiente com o sentimento de apreensão do leitor, Lovecraft nos oferece a lógica endógena do horror. Tal combinação sempre existiu na literatura clássica, como vimos em A Divina Comédia de Dante Alighieri, porém, com a popularização do horror como narrativa cristalizada em textos produzidos em larga escala da indústria de publicações ao longo do século XIX, temos o horror consolidado como gênero. 
A emoção que o gênero horror procura atingir na ficção geralmente é distinta daquela causada pelos horrores da vida real. Afinal, nota-se que os indivíduos, de certa maneira, sempre evitam sentir uma emoção horrífica em seu cotidiano. O filósofo alemão Friedrich Schiller, eu seus estudos acerca da filosofia estética no final do século XVIII, apontava que a sensibilidade do homem frente a um estado de coisas (natureza) que remetem à dor ou ao terror geralmente tem como reação um impulso de autopreservação (SCHILLER, 2011, p. 27). Mas, então, por que esse mesmo homem se submete ao horror ficcional, quando evita essa emoção no cotidiano?

Para entendermos essa diferenciação entre o horror da vida real e o horror da ficção, o filósofo estadunidense Noel Carroll adota os conceitos de horror natural para os horrores da vida real e de horror artístico para o horror ficcional (1999, p. 27). Segundo descrição de Melo, a emoção do horror artístico se refere, especificamente, a um gênero, excluindo diversas manifestações artísticas que provocam o horror e que não podem ser classificadas dentro do campo do horror natural, como as pinturas de Bosch ou os textos de Marquês de Sade, por exemplo (MELO, 2011, p. 69). Já para Carroll:

Horror artístico, por convenção, pretende referir-se ao produto de um gênero que se cristalizou, falando de modo bastante aproximado, por volta da época da publicação de Frankenstein - ponha ou tire 15 anos - e que persistiu, não raro ciclicamente, através dos romances e peças do século XIX e da literatura, dos quadrinhos, das revistas e dos filmes do século XX (CARROLL, 1999, p. 28).

O horror artístico é, para Carroll, um estado emocional de ocorrência pontual, como um ataque de nervos, e não um estado emocional contínuo, como a felicidade ou a inveja. Carroll vincula a manifestação do horror artístico à necessidade da presença da criatura monstruosa. Por outro lado, Schiller, ao apresentar os objetos da natureza em si mesmos que para nós são transformados subjetivamente em poderes temíveis pela intervenção da fantasia, diz:

A própria fantasia, ela mesma não descobre meramente o temível por comparação, mas antes o cria por sua própria conta sem possuir um fundamento objetivo suficiente para tal. Esse é o caso para o extraordinário e o indeterminado (SCHILLER, 2011, p. 43).

Os apontamentos de Schiller sobre o sublime como elemento natural e temível a sensibilidade humana, somada à proposta de Carroll (1999) de responder, 
por meio de uma teoria do horror, a questões essenciais à produção de conteúdos ligados a esse gênero narrativo, mesmo que distintos em suas premissas, formam uma síntese da personagem de terror cuja configuração pode ser observada nas produções de histórias em quadrinhos no Brasil e no mundo.

A maneira de explorar a sensibilidade humana pelo temível encarnado numa criatura e ampliado na representação do seu entorno narrativo atraiu roteiristas e desenhistas a pensar em uma fórmula capaz de transformar o gênero horror nos quadrinhos em um nicho de consumo para o público e para as editoras.

\section{Horror, arte e forma nos quadrinhos nacionais.}

Eugênio Colonnese, italiano naturalizado brasileiro, foi desenhista, roteirista e editor de histórias em quadrinhos. Fez parcerias com Osvaldo Talo e Rodolfo Zalla criando personagens como Mirza, A Mulher Vampiro, e o Morto do Pântano - este último que dividia histórias com Mirza - ambos criados em 1967 para a editora Jotaesse. Ao criar a personagem e a narrativa de O Morto do Pântano, Colonnese utilizou características sobrenaturais oriundas de personagens da literatura fantástica na forma de um morto que tem consciência e obsessão por vingança.

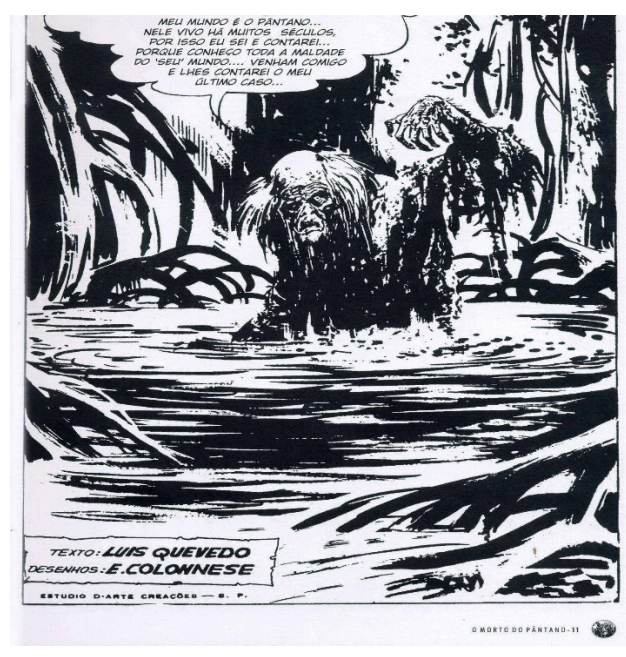

Figura 02: Imagem de abertura do quadrinho Morto do Pântano Fonte: Eugênio Colonnese/Opera Graphica Editora.

Colonnese utiliza a técnica da deformação na caracterização física da personagem para oferecer ao leitor a estética da criatura. O morto do pântano sempre recebe suas vítimas ou opositores em seu próprio ambiente, o pântano. Ele 
nunca deixa seu ambiente e aparenta uma ligação natural e mística com o lugar. Colonnesse credita ao pântano certo valor de culto, fazendo dele um ambiente intransponível, cercado de escuridão e desalento: aquilo que desperta terror antes do acontecimento propriamente dito. Note-se, nesse sentido, que o papel decisivo do ambiente na formação da narrativa e na evolução das personagens é critério fundamental para se configurar o terror como fantasia. Como apontaria Schiller:

\begin{abstract}
A fantasia mostra-se ainda mais ocupada ao fazer do secreto, do indefinido e do impenetrável um objeto do terror (...) $\mathrm{O}$ fato de ela tender justamente para o terrível, e temer mais do que espera do desconhecido, decorre da natureza do impulso de conservação que a impede. $\mathrm{O}$ repúdio atua de modo incomparavelmente mais rápido e poderoso do que o apetite, e é por isso que supomos coisas ruins, mais do que esperamos coisas boas por trás do desconhecido (SCHILLER, 2011, p. 45).
\end{abstract}

O Morto do Pântano, na medida em que incorpora o arquétipo histórico e distinto do horror artístico, também se faz original pela relação entre o extraordinário/fantasioso e o mundano, este último explicitado na ideia de que temos na caracterização da personagem, um zumbi com consciência emotiva. A personagem amedronta suas vítimas, e na mesma medida faz um equilíbrio com momentos de ternura, como na história A Pequena Silvia ${ }^{4}$, em que O Morto do Pântano salva a menina Sílvia e sua cachorrinha Fifi de dois sequestradores. A personagem do Morto do Pântano funciona como uma espécie de "má sorte" moral de quem invade seu território, o pântano - geralmente bandidos, fugitivos ou indivíduos procurados que se ocultam na zona rural por terem cometido delitos na cidade grande.

Por mais que a narrativa tenha um objetivo horripilante, ao inserir uma personagem infantil (Silvia) sendo ainda ingênua e fantasiosa em sua visão de mundo, existe uma sincronia entre as emoções do público e das personagens, exemplificando a maneira como devemos reagir na vida real quanto ao desalento de uma criança ou de uma pessoa incapaz. A mensagem da narrativa de horror às vezes permite uma mensagem de intensidade emocional que atua na mudança de comportamento tanto na personagem de ficção quanto na visão de mundo do leitor.

4 Esta história em quadrinhos se encontra na revista Mestres do Terror número sete (1982) "A Pequena Silvia" (roteiro: Osvaldo Talo, desenhos: Eugênio Colonnese) oito páginas. 


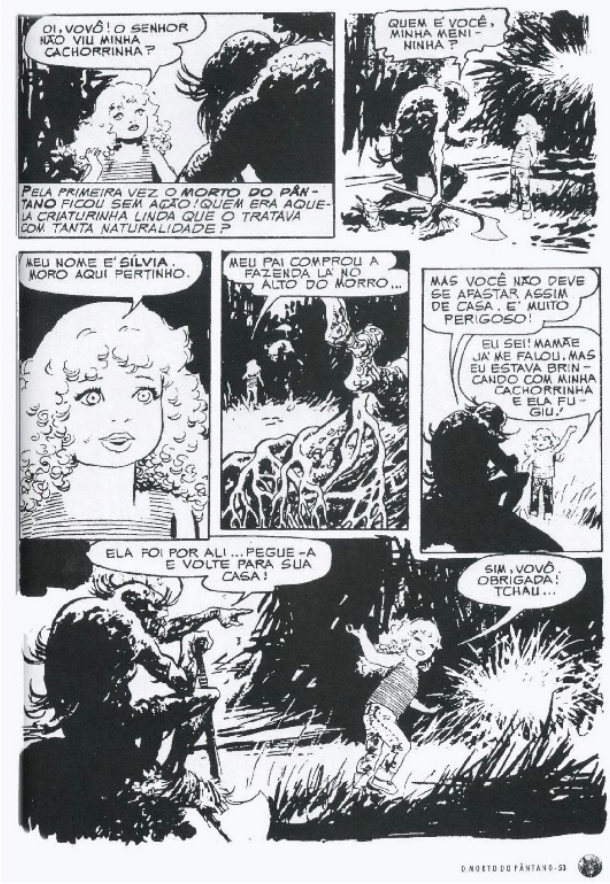

Figura 03 : Arte sequencial da pequena Silvia e o Morto do Pântano.

Fonte: Eugênio Colonnese/Opera Graphica Editora.

Na posição de anti-herói, O Morto do Pântano, com seu sarcasmo associado a uma sabedoria atemporal, protagoniza aspectos morais paradoxais. "Ao narrar as histórias o personagem se refere frequentemente às diferenças entre o "meu mundo" e o "seu mundo", demonstrando uma clara distinção entre ambientes e modos de vida conflitantes" (SILVA, 2012, p. 189). 


\section{Personagem Zé do Caixão e a primazia da repulsa}

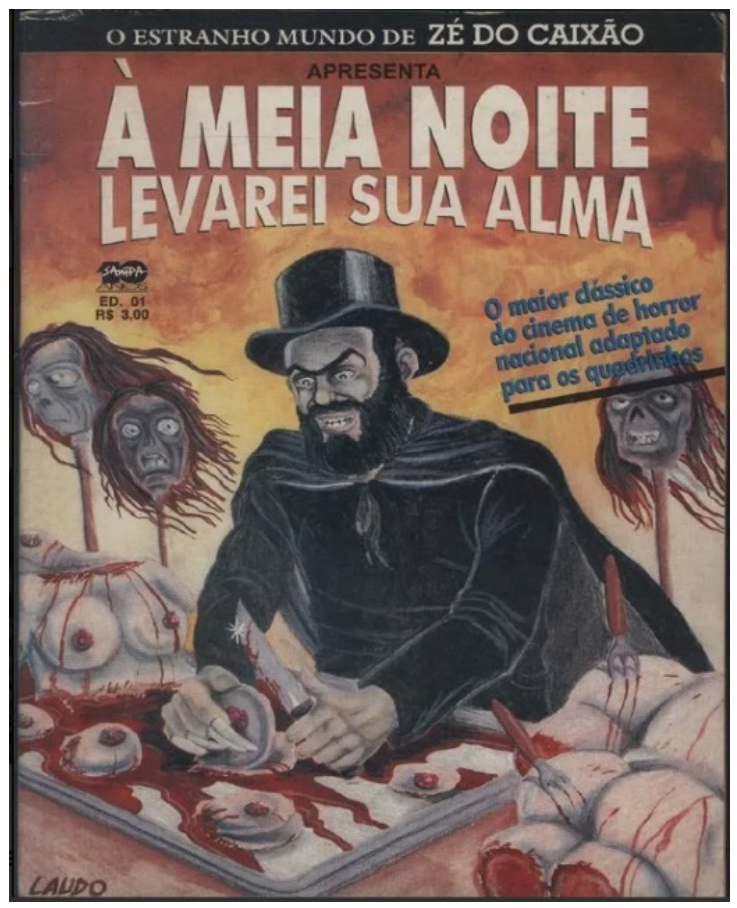

Figura 04: Imagem de capa Revista em Quadrinhos O estranho mundo de Zé do Caixão, primeira edição

Fonte: Laudo Ferreira Junior/Editora Nova Sampa

O filme de José Mojica Marins À meia-noite levarei a sua alma, filmado entre 17 de outubro e seis de novembro de 1963, devido ao sucesso do longa-metragem em sua estreia nas salas de cinema em São Paulo, em novembro de 1964, e no Rio de Janeiro, em junho de 1966, obteve ótima aceitação do grande público, e foi amplamente discutido pela crítica, que na época ficou dividida entre a qualidade do filme de absorver a atenção do espectador e a análise técnica. Sem dúvida, o impacto de público do filme de Mojica foi devido ao fato de este ter sido bem-sucedido em sua intenção de provocar horror, conforme a descrição do gênero feita sinteticamente pelo escritor de ficção estadunidense Stephen King:

O fato mais simples da ficção de horror, não importando a mídia que você escolher (...) o fundamento da ficção de horror, pode-se dizer, é este: você tem que apavorar a plateia (KING, 2003, p. 146). 
Adaptado para a arte sequencial brasileira em 1995, por Laudo Ferreira, o filme À meia-noite levarei a sua alma, protagonizado pela personagem Zé do Caixão tem, desde o início, a evidente influência do horror como gênero. A bruxa-cigana, interpretada no filme por Eucaris de Morais, faz a mesma cena de introdução da história em quadrinhos, falando diretamente ao espectador, oferecendo o sentido de narrador-participante ${ }^{5}$ para a história que será contada.

Outro elemento dramático comum ao gênero, e que está presente tanto no filme de Mojica quanto na adaptação para os quadrinhos, é a utilização frequente do sexo, muitas vezes, na forma de assassinato sexual, mutilação e rituais de sacrifício. Ao longo da década de 1970, no Brasil, ampliara-se fortemente a presença do terror associado ao erotismo desenfreado através do Editorial Idéia, que passou a importar material Italiano da Ediperiodicci e da Edifumetto, e a publicá-los a partir de 1980.

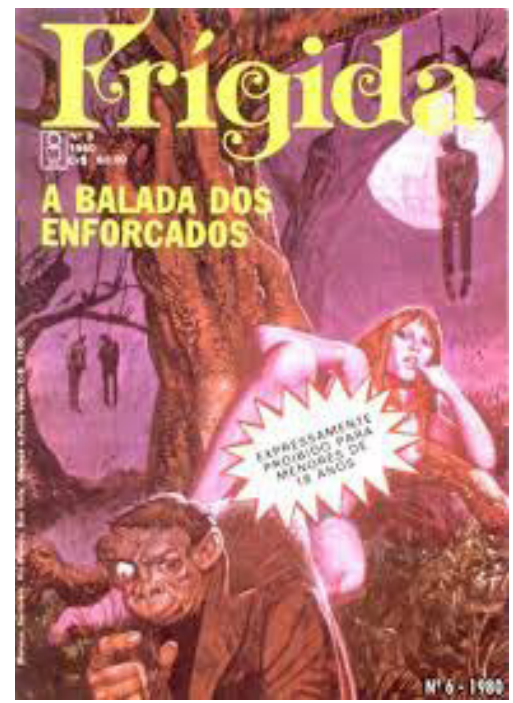

5 Um recurso característico dos quadrinhos de horror nacional utilizado nas revistas da EC Comics, a abertura da história por um anfitrião que necessariamente fará parte ou da narrativa ou em outra parte da revista. 

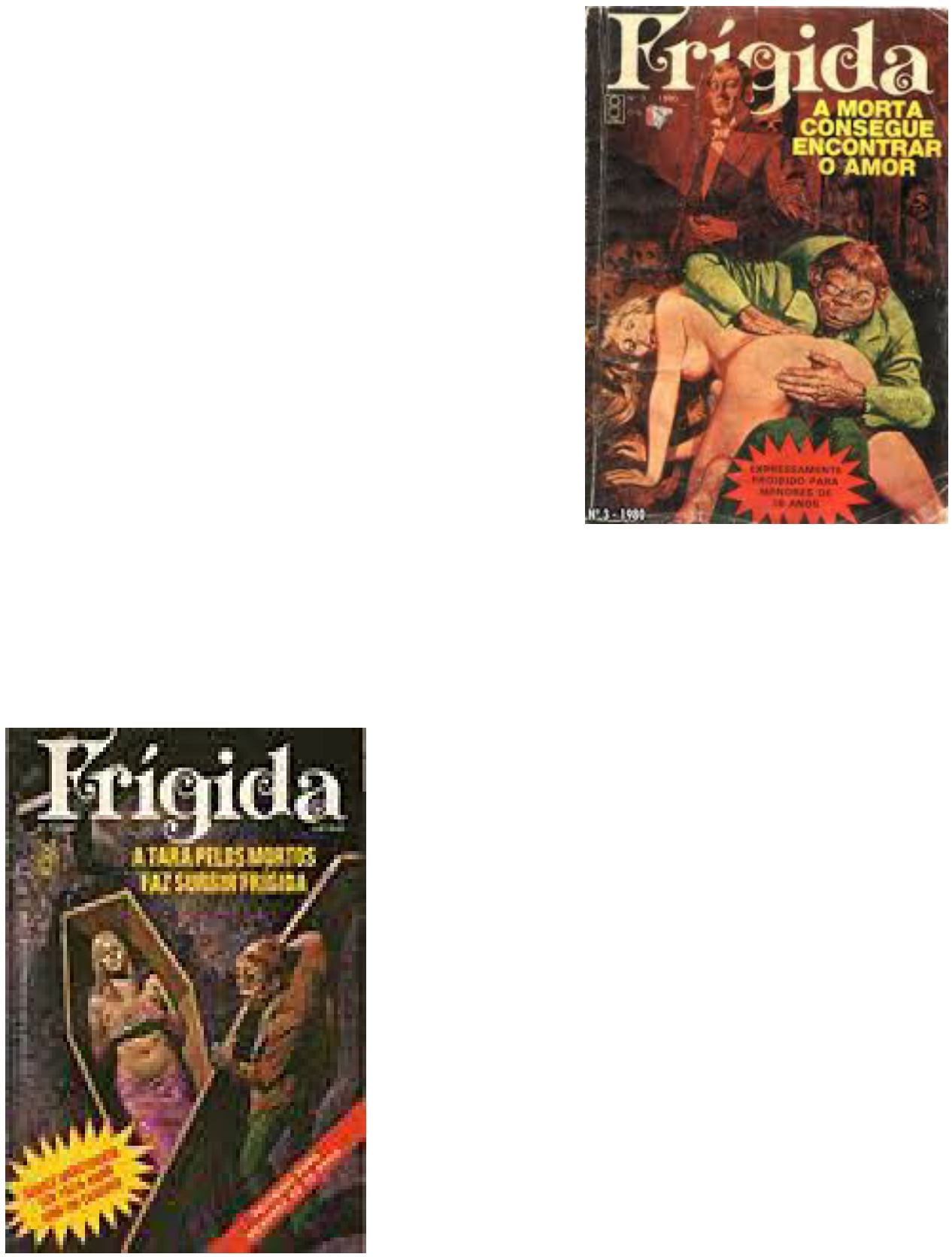
Figura 05: Montagem de capas de quadrinhos de terror e erotismo- Frígida, n³, $n^{\circ} 1, n^{\circ} 6$, capa de Alessandro Biffignandi, junho/1980, Idéia Editorial - SP

Fonte: Sthar Mar Vasconcelos/Guia dos Quadrinhos

Melo (2011) usa uma distinção nas personagens de horror em que as respostas emocionais da criatura/monstro divergem das demais personagens. Denominadas por Carroll (1999, p. 34) como "personagens positivas", essas personagens não monstruosas convergem com os sentimentos do leitor ao sentirem repulsa pelos monstros dentro das narrativas, pois, como observa Melo, "o horror é um gênero em que as respostas emocionais da audiência são sugeridas pelas respostas emocionais das personagens positivas" (2011, p. 72-73).

Mas a adaptação feita por Laudo Ferreira nos anos 1990 não foi a primeira vez em que Zé do Caixão fez aparições nos quadrinhos brasileiros. Na série de revistas em quadrinhos idealizada por Rubens Lucchetti e desenhada por Nico Rosso, O estranho mundo de Zé do Caixão, nos anos 1960, Zé do Caixão colocava suas vítimas gradativamente em um estado de aprisionamento mental e espiritual antes de o acontecimento dramático se apresentar, ou seja, a apreensão dos ambientes construídos deflagrava o sentimento de terror que precedia o fato horrífico. A série incorporava uma combinação da tradição de personagens de horror, da linguagem dos quadrinhos e das fotonovelas em um mesmo produto, como descreve Silva:

(...) apresentando narrativas híbridas, onde os desenhos de Nico Rosso eram intercalados com a fotografia de Luiz Fidélis Barreira, representando Zé do Caixão como apresentador da narrativa. Repetindo o modelo inaugurado pela EC Comics, vemos a personalidade do narrador materializado na figura do próprio Zé do Caixão em sua representação fotográfica, utilizada tal como a estratégia típica da fotonovela em promover os ídolos da mídia (SILVA, 2012, p. 254). 
Planejada inicialmente para ser uma reprodutora parcial das histórias de Zé do Caixão no cinema, a série da EC comics ofereceu originalidade estrutural na representação, que "(...) estendia-se à diagramação e ao desenho dos quadros pontiagudos, criando tensão e irregularidade à composição estrutural da página.” (SILVA, 2012, p. 254). A convergência da linguagem editorial e os aspectos gráficos aliados a um realismo fotográfico transformam a personagem Zé do Caixão - narrador e participante - em uma espécie de referência da estética brasileira de personagem de horror. Para Silva:

Um personagem brasileiro híbrido do imaginário local e do estrangeiro, figurando entre cinema, quadrinhos e televisão, completamente integrado e sintonizado com os ideais empresariais da época, no sentido de construção das tão sonhadas indústrias culturais (SILVA, 2012, p. 259).

No que diz respeito à construção da história em si, a repulsa sobre o relato apresentado toma ares sobrenaturais e se radicaliza quando o acontecimento chega ao clímax, que se apresenta em uma variação de sobrenatural, esquartejamento, erotismo, rituais satânicos, corrupção de pensamento, aliciamento etc. De fato, o hibridismo como síntese em Zé do Caixão, formalizado por Silva, também pode remeter a uma reação de repulsa geral por parte do leitor, intensificando ainda mais os critérios de audiência das obras.

Podemos dizer que as "personagens positivas", enquanto vítimas ou espectadoras do fato horrífico, experimentam a repulsa ante as ameaças ou aos elementos associados aos monstros ou ambientes nocivos. Elas são, de alguma maneira, a forma de como o leitor se encaixar na história, de maneira imersiva e com estado de repulsa. Esse efeito de espelho, segundo Carroll, é aspecto-chave no gênero de horror em que "a resposta do público deva repetir certos elementos do estado emocional dos personagens" (CARROLL, 1999, p. 34).

\section{Considerações finais}

O presente estudo não buscou referendar o ponto de vista editorial dos quadrinhos ou esmiuçar uma cronologia exata de lançamentos do mercado. O foco foi determinar aspectos das personagens de horror brasileiras que se perpetuaram como estruturas fundamentais de linguagem e de gênero, sendo as histórias em quadrinhos um dos locais de maior e mais recorrente exploração do segmento.

No decorrer de nossa reflexão, consideramos o terror e o horror como elementos combinatórios que, antes de se formalizarem como um gênero literário, fizeram parte de um poder simbólico de tradição religiosa cristalizado na cultura ocidental. Os exemplos da produção de horror nos quadrinhos brasileiros de Zé do 
Caixão e O Morto do Pântano são relevantes sob muitos aspectos. Entende-se, por meio deles, muitas transformações e reflexos do imaginário social. Suas narrativas nos direcionam ao esboço de um horror híbrido, combinando fatores que vêm desde a literatura clássica, como personificação da criatura grotesca e sua relação estranha, com a perspectiva realista mundana. As personagens carregam um perfil psicológico de conflito natural com a existência, geralmente assistida e traduzida pelo leitor como "forma distorcida" de visão de mundo.

Os objetivos das personagens podem navegar de condição moral justa até execuções sem nenhuma justificativa plausível, causando uma sensação de imprevisibilidade na evolução da narrativa. Embora as personagens analisadas tivessem enfoques divergentes na ênfase moral e de ação dramática, as duas produções têm o poder de sintetizar emoções como medo, terror, horror, repulsa, ojeriza, dentre outras, e podem ser colocadas como referencial estético e narrativo, dando abertura para a extensão dessas personagens no mercado ou para futuros personagens de histórias em quadrinhos brasileiras.

\section{Referências Bibliográficas}

ALIGHIERI, Dante. A Divina Comédia: Inferno. São Paulo: Ed. 34, 1998.

BAGNARIOL, Piero. ALIGHIERI, Dante. A Divina Comédia em quadrinhos. São Paulo: Editora Peirópolis, 2011.

CARROLL, Noel. A filosofia do horror ou paradoxos do coração. Campinas: Papirus, 1999.

JUNIOR, Gonçalo. Enciclopédia dos Monstros. São Paulo: Ediouro, 2008.

LOVECRAFT, Howard Phillips. O horror sobrenatural na literatura. Rio de Janeiro: Francisco Alves, 1987.

MANN, Carlos (Org.). O morto do pântano. São Paulo: Opera Graphica Editora, 2005.

MELO, Marcelo Briseno Marques de. Autópsias do horror: a personagem de terror no Brasil. São Paulo: LCTE Editora; FAPESP, 2011.

RADCLIFFE, Ann. On the supernatural in poetry. The New Monthly Magazine, v. 7, p. 145-152, 1826. Disponível em: <https://en.wikipedia.org/wiki/Ann_Radcliffe>. Acesso em: 27 fev. 2019.

SANTOS NETO, Elydio dos. Os quadrinhos poético-filosóficos de Gazy Andraus: Provocações de uma visão crítica, espiritual e afirmativa da vida. In: XXX Congresso Brasileiro de Ciências da Comunicação, 2007, Santos. Anais... São Paulo: Intercom, 2007. Disponível em: <http://www.intercom.org.br/papers/nacionais/2007/resumos/R0463-1.pdf>. Acesso em: 3 fev. 2019. 
SÜSSEKIND, Pedro. Friedrich Schiller: do sublime ao trágico. Belo Horizonte: Autêntica Editora, 2011.

SILVA, Luciano Henrique Ferreira da. O gênero de horror nos quadrinhos brasileiros: linguagem, técnica e trabalho na consolidação de uma indústria - 1950-1967. 2012. 316 f. Tese (Doutorado em Tecnologia) - Programa de Pós-Graduação em Tecnologia, UTP, Curitiba, 2012.

The aesthetics of the horror character in Brazil: Coffin Joe and O Morto do Pântano [The Dead of the Swamp]

\begin{abstract}
This paper considers the fictional characters Coffin Joe and O Morto do Pântano [The Dead of the Swamp] as references of structure and style of the horror genre in Brazilian comics. For a methodological scope based on observational reading, will be treated aspects of these characters whose references are found in Western classical literature. To reach these references, we intend to draw a brief historical overview of the horror and its characters in three correlated historical moments of literature: 1. In 13th Century, when religious-social control caused, at the same time, fear and respect for the supernatural; 2. In the begginings of the 19th Century, when horror was consolidated as a literary genre, and offered originality and autonomy for the narratives; 3 . The Late 19th Century onwards, with the proliferation of horror as an artistic reference and mass consumption.
\end{abstract}

\title{
Keywords
}

Horror; Terror; Comics; Coffin Joe; O Morto do Pântano [The Dead of the Swamp]. 